\title{
KAJIAN ETNOMATEMATIKA : KONSEP MATEMATIS PRODUSEN JAMU GENDONG TERHADAP PEMBELAJARAN MATEMATIKA
}

\author{
${ }^{1}$ Nazar Ramdani \\ ${ }^{1}$ Pendidikan Matematika, Fakultas Keguruan dan Ilmu Pendidikan, Universitas Muhammadiyah Sukabumi
}

\begin{abstract}
Abstrak
Kebiasaan masyarakat dalam mengkonsumsi suatu produk kesehatan tidak pernah terlepas, dari sejak jamu dulu banyak orang membutuhkannya. Salah satu yang menjadi alasan seorang produsen jamu gendong bermunculan pada saat itu. Produsen jamu gendong merupakan usaha industri rumah tangga yang menjajakan beberapa jamu dalam bentuk botolan hasil dari racikannya yang nantinya akan menghasilkan suatu campuran jamu yang diinginkan oleh penjual tersebut untuk diberikan kepada pelanggannya, dari peristiwa tersebut terdapat beberapa konsep matematis yang diberikan salah satunya Kombinasi dan Permutasi, konsep tersebut dapat dikaitan terhadap pembelajaran matematika salah satu dalam pengajian soal cerita guna memperkenalkan etnomatematika terhadap perspektif kebiasaan orang terdahulu.
\end{abstract}

Kata Kunci: Konsep Matematis, Pembelajaran Matematika, Jamu Gendong.

\section{PENDAHULUAN}

Jamu merupakan salah satu obat tradisional yang sangat diminati dan digemari masyarakat, dikarenakan harganya yang terjangkau dan mudah serta mudah diperoleh. Jamu gendong merupakan industri rumah tangga yang dibuat serta diolah dengan peralatan yang sederhana, pembuatannya cukup mudah berasal dari bahan baku dan banyak tersedia di pasar atau di toko bahan baku jamu (Suharmiati dan Handayani, 2005).

Usaha jamu gendong terus berkembang sesuai dengan kebutuhan masyarakat yang banyak menggunakannya sebagai minuman penyegar atau obat penyakit ringan. Konsumen jamu gendong banyak tersebar baik di pedesaan maupun perkotaan dan diperkirakan semakin meningkat dari hari ke hari. Hal ini terbukti dengan meningkatnya jumlah produsen jamu gendong.

Menurut data Departemen kesehatan, peningkatan jumlah penjual jamu gendong cukup pesat yaitu dari 13.128 orang pada tahun 1989 menjadi 25.077 orang pada tahun 1995. Angka tersebut barangkali masih di bawah angka sebenarnya, mengingat sangat banyak penjual jamu gendong sehingga besar kemungkinan banyak yang tidak terdata (Suharmiati, 2003).

Penggunaan jamu gendong bisa digunakan dalam waktu yang cukup lama karena ramuannya terdiri dari bahan alami serta dalam pemakaian bertujuan untuk menjaga kesehatan. Hal ini merupakan keuntungan tersendiri bagi penjual jamu karena dengan demikian konsumen akan merasakan mamfaat jamu yang dikehendakinya. Produsen jamu gendong merupakan orang yang membuat suatu produk jamu berupa jamu yang telah diracik kedalam beberapa botol yang telah disediakan. Para produsen jamu gendong pada awalnya banyak bermunculan pada masa kolonial belanda, kebanyakan dari konsumen (pembeli) mereka terdiri dari kelas atas sampai kelas bawah, para konsumen tersebut sangat meminati terhadap penjual jamu gendong tersebut, mereka menjajakan beberapa macam jamu yang ada didalam botol yang sudah dibuat sesuai dengan resep terdahulu (turun temurun) dan kemudian yang nantinya siap diracik dengan menuangkan beberapa macam campuran kedalam gelas minuman yang berasal dari botol tersebut, bahkan banyak resep dalam racikan jamu itu sudah ada sejak jaman kerajaan Majapahit. Salah satu cara untuk mempertahankan keasliaan dalam peracikan jamu tersebut mereka mengunakan konsep matematis yang diintegrasikan terhadap Etnomatematika, yang kemudian diterapkan pada pembelajaran matematika.

Konsep matematis menurut Gagne (Arsat, 2007: 8) mengemukakan bahwa konsep dalam matematis adalah ide abstrak yang menyakinkan seseorang dalam mengklasifikasikan objek (Komarudin et al., 2020) dan suatu kejadian terhadap contoh atau bukan contoh dari suatu objek yang akan dituju (Agustiana et al., 2019; Komarudin et al., 2020; Wahyuni et al., 2019). Selanjutnya, Etnomatematika menurut Tandiling (2013), merupakan matematika yang diterapkan oleh kelompok budaya tertentu, kelompok buruh/petani, anak- anak dari masyarakat kelas tertentu, kelas-kelas profesional dan sebagainya. Jika dipandang dari sudut pandang riset maka etnomatematika dapat didefinisikan sebagai antropologi budaya (cultural antropology of 
mathematics) dari matematika (Aini et al., 2018; Rahayu et al., 2020; Rohmaini et al., 2020).

Pembelajaran matematika adalah kegiatan penyaluran pengalaman belajar guru matematika kepada siswa melalui beberapa serangkaian kegiatan yang sudah direncanakan sehingga siswa memperoleh pemahaman apa yang ia pelajari.

\section{METODE}

Jenis penelitian ini merupakan penelitian kualitatif dengan pendekatan etnografi Kirk dan Miller (1986) mendefinisikan penelitian dalam metode kualitatif merupakan sebuah tradisi tertentu dalam ilmu pengetahuan yang secara fundamental terhadap pengamatan manusia dalam suatu kawasan sendiri serta berhubungan dengan orang-orang tertentu.

\section{HASIL DAN PEMBAHASAN}

\section{Konsep Matematis dalam Produsen Jamu Gendong}

Sejak jaman dulu, para peracik jamu pada masa itu mempertahan beberapa unsur yang bersifat matematis, utamanya dalam mengelompokan beberapa herbal guna meracik jamu dan proses peracikan jamu itu dengan membuat beberapa campuran jamu yang akan dibuat, kemudian siap digunakan oleh orang lain. Dasar dalam meracik jamu tersebut tidak dilakukan secara sembarang, terdapat beberapa metode yang harus dilakukan agar mendapat hasil racikan jamu yang diinginkan oleh produsen tersebut guna diberikan kepada konsumen. Contohnya : Seorang produsen jamu gendong biasanya membawa minimal 8 campuran jamu, misalnya terdiri dari beras kencur, kunyit asam, jamu pahitan, jamu watukan, jamu cabe payung, jamu galian singset, jamu kuat dan terakhir jamu leruh kencur.

Para peracik jamu mengetahui dengan sangat benar bagaimana melakukan langkah dalam meracik jamu yang dihasilkan dari beberapa botol sesuai dengan keinginannya. Dari peristiwa tersebut telah dibuktikan akan terjadinya suatu menggabungkan beberapa objek (objek berupa botol jamu) dari suatu grup (produsen jamu gendong) tanpa memperhatikan urutan dan juga terlihat penyusunan kembali suatu kumpulan objek dalam urutan yang berbeda dari urutan yang semula. Sehingga dari beberapa hal tersbut menghasilkan berbagai cara peracikan dalam campuran beberapa jamu. Dari penjelaskan tersebut menghasilkan suatu pengertian kombinasi \& permutasi dalam produsen jamu gendong.

\section{a. Kombinasi}

Istilah kombinasi dalam matematis

kombinatorik berarti himpunan objek yang tidak mementingkan urutan sedangkan permutasi merupakan kumpulan objek dalam urutan yang berbeda dari urutan yang semula. Kombinasi berbeda dengan permutasi yang mementingkan urutan objek. Perkataan kombinasi memiliki sebutan lainnya yaitu gabungan, padu-kepaduan atau perpaduan. Rumus kombinasi sebagai berikut :

$$
C(x, y)=\frac{x !}{(x-y) ! y !}
$$

Keterangan ;

$x=$ Jumlah seluruh objek

$y=$ Objek yang akan diperintahkan

Pengaitan kombinasi dalam peracikan dalam pencampuran jamu yang dilakukan oleh produsen jamu gendong, sangat berkaitan erat. Contoh Soal.1

Penjual jamu hanya membawa 8 macam botol jamu, seadainya penjual jamu tersebut hanya mencampurkan 2 botol jamu saja untuk menghasilkan racikan jamu. Banyak racikan jamu yang terjadi adalah ...

Diketahui:

$$
\text { Jawab }
$$

$$
\begin{array}{ll}
\mathrm{x}=8 & \begin{array}{l}
\text { menyatakan jumlah botol jamu } \\
\text { menyatakan jumlah botol jamu }
\end{array} \\
\mathrm{y}=2 & \begin{array}{l}
\text { yang akan dicampurkan. } \\
8 !
\end{array} \\
C(8,2)=\frac{8 !}{(8-2) ! 2 !}=\frac{8 \times 7 \times 6 !}{6 ! 2 !}=\frac{56}{6 ! 2 !}=28
\end{array}
$$

Jadi, banyaknya racikan jamu sebanyak 28 .

\section{Contoh Soal.2}

Penjual jamu membawa 8 macam botol jamu, 3 botol diantaranya jamu yang pahit. Hitunglah banyaknya macam jamu apabila penjual jamu tersebut mencampurkan 2 botol jamu pahit dan 1 botol jamu tidak pahit adalah ...

$\underline{\text { Jawab }}$

Diketahui :

PEMBUKTIAN
Misalkan 8 botol jamu : $\{A, B, C, D, E, F, G, H\}$
Hasil racikan dari 2 botol jamu : $\{A B, A C, A D, A E, A F, A G, A F, B C, B D, B E, B F, B G$,
BH, $C D, C E, C F, C G, C H, D E, D F, D G, D H, E F, E G, E H, F G, F H, G H\}=28$
TERBUKTI

Jamu pahit : 3 Botol

Jamu tidak pahit $\quad 5$ Botol

Kombinasi 2 jamu pahit dari 3 :

$C(3,2)=\frac{3 !}{(3-2) ! 2 !}=\frac{3 !}{1 ! 2 !}=3$

Kombinasi 1 Jamu tidak pahit dari 5:

$C(5,1)=\frac{5 !}{(5-1) ! 1 !}=\frac{5 !}{4 ! 1 !}=5$

Dengan kedua susunan yang telah ditentukan agar dapat ditemukan seluruh kombinasi yang dimaksud pada soal, perlu dikalikan satu sama lain :

$C(3,2) \times C(5,1)=3 \times 5=15$ 


\begin{tabular}{|c|c|c|c|c|c|c|c|}
\hline \multicolumn{8}{|c|}{ PEMBUKTIAN } \\
\hline \multicolumn{8}{|c|}{ Misalkan } \\
\hline \multicolumn{5}{|c|}{$\begin{array}{l}5 \text { botol jamu tidak pahit } \\
3 \text { botol jamu pahit }\end{array}$} & \multicolumn{3}{|c|}{$\begin{array}{l}:\{A, B, C, D, E\} \\
:\{F, G, H\}\end{array}$} \\
\hline \multicolumn{8}{|c|}{$\begin{array}{l}\text { Racikan jamu apabila mencampuran, } 2 \text { botol jamu pahit dan } 1 \text { jamu tidak pahit, } \\
\text { maka dapat dihasilkan racikan sebagai : }\end{array}$} \\
\hline A & $\mathrm{F}$ & G & A & $\mathrm{F}$ & н & $A \quad 0$ & н \\
\hline в & $\mathrm{F}$ & $\circ$ & в & $\mathrm{F}$ & н & в 0 & н \\
\hline c & $\mathrm{F}$ & $\circ$ & c & $\mathrm{F}$ & н & c $\quad$ o & н \\
\hline D & F & $\mathrm{G}$ & D & $\mathrm{F}$ & н & D 0 & н \\
\hline E & $\mathrm{F}$ & ${ }^{\circ}$ & E & $\mathrm{F}$ & н & E $\quad G$ & н \\
\hline \multicolumn{8}{|c|}{ Terdapat 15 macam jamu } \\
\hline \multicolumn{8}{|c|}{ TERBUKTI } \\
\hline
\end{tabular}

Banyaknya racikan sebanyak 15 buah

\section{b. Permutasi}

Permutasi merupakan proses mengembalikan objek objek tersebut pada urutan yang baku (sesuai ketentuan). Rumus permutasi yaitu sebagai berikut :

$$
P(a, b)=\frac{a !}{(a-b) !}
$$

Keterangan ;

$a=$ Jumlah seluruh objek

$b=$ Objek yang akan diperintahkan

Jenis Jenis permutasi antara lain :

$>$ Permutasi dari seluruh unsur yang sama dirumuskan dengan :

$n !$

$>$ Permutasi n, dimisalkan p, q, r menyatakan banyaknya unsur yang sama dirumuskan dengan:

$$
\frac{n !}{p ! q ! r !}
$$

Permutasi siklis (melingkar) dirumuskan dengan :

$$
(n-1) \text { ! }
$$

Pengaitan permutasi dalam peracikan dalam pencampuran jamu yang dilakukan oleh produsen jamu gendong, sangat berkaitan erat pula.

Contoh Soal.1

Dalam meracik jamu pegal linu diperlukan jamu kunyit asam, jamu pahitan, dan jamu cabe payung.banyaknya pencampuran yang mungkin terjadi adalah ...

\section{$\underline{\text { Jawab }}$}

Banyak jenis jamu :

\{jamu kunyit asam, jamu pahitan, jamu cabe payung

$\mathrm{n}=3$

"Banyaknya pencampuran yang mungkin terjadi" dapat dikatakan sebagai permutasi dari seluruh unsur yang sama. Jadi, $n !=3 !=3 \times 2 \times 1=6$ cara

\begin{tabular}{l} 
Pembuktian: \\
Jenis jamu \{ Jamu kunyit asam, Jamu pahitan, Jamu cabe payung \} \\
Banyaknya pencampuran yang terjadi: \\
\begin{tabular}{|c|l|l|l|}
\hline Cara & \multicolumn{3}{|l|}{} \\
\hline 1 & Jamu kunyit asam & Jamu pahitan & Jamu cabe payung \\
\hline 2 & Jamu kunyit asam & Jamu cabe payung & Jamu pahitan \\
\hline 3 & Jamu pahitan & Jamu kunyit asam & Jamu cabe payung \\
\hline 4 & Jamu pahitan & Jamu cabe payung & Jamu kunyit asam \\
\hline 5 & Jamu cabe payung & Jamu kunyit asam & Jamu pahitan \\
\hline 6 & Jamu cabepayung & Jamu pahitan & Jamu kunyit asam \\
\hline Terdapat 6 cara & & \\
TERBUKTI &
\end{tabular} \\
\hline
\end{tabular}

Banyaknya pencampuran sebanyak 6 cara.

2. Pengembangan Etnomatematika dalam Pembelajaran Matematika

Beberapa konsep matematis yang dianalisis seperti Kombinasi dan Permutasi merupakan sub materi pembelajaran Matematika di tingkat SMA/MA/SMK. Dengan dikaitkanya dengan pembelajaran etnomatematika tersebut, para siswa dituntut untuk senastiasi berpikir luas dalam menghadapi penerapan/aplikasi soal cerita terhadap konsep matematis terhadap sub materi tersebut.

\section{PENUTUP}

\section{Simpulan}

Hasil dari analisis data dan pembahasan yang telah dilakukan dapat disimpulkan bahwa terdapat etnomatematika terhadap produsen jamu gendong. Etnomatematika tersebut memuat beberapa konsep matematis diantaranya kombinasi dan permutasi, dalam hal itu juga konsep tersebut dapat diaplikasikan kedalam pembelajaran Matematika di tingkat SMA/MA/SMK

\section{Saran}

Saran yang dapat dikemukakan oleh peneliti adalah untuk peneliti selanjutnya diharapkan melakukan pengembangan konsep matematis lain terhadap kajian tersebut.

\section{DAFTAR PUSTAKA}

Sarwoedi, Sarwoedi. 2018. "Efektifitas Etnomatematika Dalam Meningkatkan Kemampuan Pemahaman Matematika Siswa." Jurnal Pendidikan Matematika Raflesia 3.2.

Purwaningsih, Ernie H. 2013. "Jamu, Obat Tradisional Asli Indonesia: Pasang Surut Pemanfaatannya Di Indonesia." eJournal Kedokteran Indonesia.

Limyati, D. A., and B. L. L. Juniar. 1998. "The Microbial Contamination of Its Raw Jamu Gendong, A Kind of Traditional Medicine in Indonesia Materials and Endproduct." Journal of Ethnopharmacology 63.3.

Agustiana, N., Supriadi, N., \& Komarudin, K. (2019). Meningkatkan Kemampuan Penalaran 
Matematis dengan Penerapan Pendekatan Bridging Analogy Ditinjau dari Self-Efficacy. Inovasi Pembangunan: Jurnal Kelitbangan, 7(1), 61-61.

Aini, E. P., Masykur, R., \& Komarudin, K. (2018). Handout Matematika berbantuan Etnomatematika Berbasis Budaya Lokal. Desimal: Jurnal Matematika, 1(1), 73-79. https://doi.org/10.24042/djm.v1i1.1950

Komarudin, K., Puspita, L., Suherman, S., \& Fauziyyah, I. (2020). Analisis Pemahaman Konsep Matematis Peserta Didik Sekolah Dasar: Dampak Model Project Based Learning Model. DIDAKTIKA TAUHIDI: Jurnal Pendidikan Guru Sekolah Dasar, 7(1), 43-53.

Rahayu, A. P., Snae, M., \& Bani, S. (2020). ETNOMATEMATIKA PADA KAIN TENUN LIPA KAET. MEGA: Jurnal Pendidikan Matematika, 1(1), 16-24.

Rohmaini, L., Netriwati, N., Komarudin, K., Nendra, F., \& Qiftiyah, M. (2020). Pengembangan Modul Pembelajaran Matematika Berbasis Etnomatematika Berbantuan Wingeom Berdasarkan Langkah Borg And Gall. Teorema: Teori Dan Riset Matematika, 5(2), 176-186.

Wahyuni, T., Komarudin, K., \& Anggoro, B. S. (2019). Pemahaman Konsep Matematis Melalui Model WEE Dengan Strategi QSH Ditinjau Dari Self Regulation. AKSIOMA: Jurnal Program Studi Pendidikan Matematika, 8(1), 65-72.

Dian, Christiana Kartika; KRISWANDANI, Kriswandani; RATU, Novisita. 2018. "Analisis Kemampuan Berpikir Reflektif Dalam Menyelesaikan Soal Cerita Materi Persegi Bagi Siswa Kelas VIII SMP Kristen 02 Salatiga Tahun Ajaran 2017/2018." Paedagoria: Jurnal Kajian, Penelitian dan Pengembangan Kependidikan, 9.1: 1-4.

Kementrian Pendidikan dan Kebudayaan. 2014. Buku Guru Matematika SMA/MA/SMK Kelas XI. Jakarta: Kementrian Pendidikan dan Kebudayaan. 